\title{
Ramipril mitigates radiation-induced impairment of neurogenesis in the rat dentate gyrus
}

\author{
Kenneth A Jenrow ${ }^{1 *}$, Stephen L Brown ${ }^{2}$, Jianguo Liu ${ }^{2}$, Andrew Kolozsvary², Karen Lapanowski ${ }^{2}$, Jae Ho Kim²
}

\begin{abstract}
Background: Sublethal doses of whole brain irradiation (WBI) are commonly administered therapeutically and frequently result in late delayed radiation injuries, manifesting as severe and irreversible cognitive impairment. Neural progenitors within the subgranular zone (SGZ) of the dentate gyrus are among the most radiosensitive cell types in the adult brain and are known to participate in hippocampal plasticity and normal cognitive function. These progenitors and the specialized SZG microenvironment required for neuronal differentiation are the source of neurogenic potential in the adult dentate gyrus, and provide a continuous supply of immature neurons which may then migrate into the adjacent granule cell layer to become mature granule cell neurons. The extreme radiosensitivity of these progenitors and the SGZ microenvironment suggests the hippocampus as a prime target for radiation-induced cognitive impairment. The brain renin-angiotensin system (RAS) has previously been implicated as a potent modulator of neurogenesis within the SGZ and selective RAS inhibitors have been implicated as mitigators of radiation brain injury. Here we investigate the angiotensin converting enzyme (ACE) inhibitor, ramipril, as a mitigator of radiation injury in this context.
\end{abstract}

Methods: Adult male Fisher 344 rats received WBI at doses of 10 Gy and 15 Gy. Ramipril was administered beginning 24 hours post-WBI and maintained continuously for 12 weeks.

Results: Ramipril produced small but significant reductions in the deleterious effects of radiation on progenitor proliferation and neuronal differentiation in the rat dentate gyrus following $10 \mathrm{~Gy}$-WBI, but was not effective following 15 Gy-WBI. Ramipril also reduced the basal rate of neurogenesis within the SGZ in unirradiated control rats.

Conclusions: Our results indicate that chronic ACE inhibition with ramipril, initiated 24 hours post-irradiation, may reduce apoptosis among SGZ progenitors and/or inflammatory disruption of neurogenic signaling within SGZ microenvironment, and suggest that angiotensin II may participate in maintaining the basal rate of granule cell neurogenesis.

\section{Background}

Sublethal doses of whole brain irradiation (WBI) are commonly administered therapeutically (cranial radiation), and might also be administered inadvertently in the event of a nuclear accident or radiological attack [1-3]. Clinical data derived from patients receiving cranial radiation suggest that long term survivors of such exposures are at risk for developing late delayed effects manifesting as chronic and irreversible cognitive impairment and dementia [3]. These late delayed effects are routinely observed following WBI doses substantially

\footnotetext{
* Correspondence: nskje@neuro.hfh.edu

'Henry Ford Hospital, Department of Neurosurgery, 3074 E\&R Building, 2799 W Grand Boulevard, Detroit, Michigan 48202, USA
}

below thresholds for vasculopathy or demyelination, but sufficient to impair granule cell neurogenesis within the hippocampus along with electrophysiological and behavioral measures of hippocampal plasticity [4-12]. These observations suggest that impaired neurogenesis and plasticity within the hippocampus may contribute to cognitive impairment in humans exposed to WBI, and that mitigating radiation damage to these progenitors and/or preserving their neurogenic potential might be a successful strategy for reducing the development of these late delayed effects.

The learning and memory functions of the hippocampus have been associated with a coordinated neurogenic response that occurs within the subgranular zone (SGZ) 
of the dentate gyrus, one of only two regions in the adult brain (the other being the subventricular zone) where the capacity for neurogenesis is retained throughout life $[4,13,14]$. The unique microenvironment within the SGZ induces vascular adventitial stem cells to differentiate into rapidly dividing progenitors, which are typically found in discrete clusters surrounding their source microvessels $[4,5,15]$. Signaling within the SGZ microenvironments defined by these clusters is required for neuronal differentiation among the progenitors and coordinates the rate of neurogenesis with the demands of hippocampally-mediated learning and memory processes $[13,14]$. Immature neurons may then migrate away from these clusters into the adjacent granule cell layer $(\mathrm{GCL})$ where they may gradually mature to assume the morphological and functional characteristics of granule cell neurons $[9,16]$. The proportion of these neurons that survive to become mature granule cell neurons is generally small but can be increased by behavioral activity, including physical exercise, environmental enrichment, and spatial learning [16]. During their maturation, which requires approximately 65 days, these new neurons are hyperexcitable and possess an enhanced potential for synaptic plasticity $[11,16]$.

Ablating neurogenesis within the dentate gyrus impairs hippocampal plasticity and performance in spatial learning tasks, and the severity of this impairment is proportional to the extent of damage specific to the granule cell progenitor population $[5,10,11,14,17]$. Radiation dose-dependent decreases in granule cell neurogenesis are well established following WBI and result from the loss of neural progenitors, via apoptosis and mitotic catastrophe, and a disruption of neurogenic signaling, via the dispersion of progenitor clusters within the SGZ. These pathologies are inversely correlated with radiation dose-dependent increases in activated microglia within the dentate gyrus [18]. In vitro studies have revealed that activated microglia contribute to the disruption of neurogenesis in this context by releasing interleukin- 6 (IL-6), interleukin-1 $\beta$ (IL-1 $\beta$ ), and tumor necrosis factor- $\alpha$ (TNF- $\alpha$ ), proinflammatory cytokines which induce a nonspecific decrease in cell survival as well as a selective decrease in neuronal differentiation among progenitor cells $[9,18]$. Administering the anti-inflammatory drug, indomethacin, or the PPAR $\alpha$ agonist, fenofibrate, prior to irradiation partially prevents microglial activation and the decrease in neurogenesis post-irradiation. Thus reducing inflammation within the dentate gyrus post-irradiation might similarly reduce the deleterious effects of WBI on granule cell neurogenesis $[9,19]$.

Inhibiting the renin-angiotensin system (RAS) has proven to be one of the more successful strategies for mitigating the development of late delayed effects following WBI doses above the necrotic threshold [20-22].
Though traditionally viewed as a blood-borne hormonal system, a number of intraorgan RASs have also been identified [23]. In the brain, RAS components are localized in both neuronal and glial cells which release renin and angiotensinogen. These peptides interact to produce angiotensin I, a biologically inactive decapeptide that is subsequently cleaved by angiotensin I converting enzyme (ACE) to produce the effector octapeptide angiotensin II (Ang II). Ang II is a potent vasopressor that exerts its effects by binding to G-protein receptors, AT1R and AT2R, which are broadly distributed in the brain and particularly dense in the hippocampus [23]. After tissue injury, AT2Rs are upregulated and Ang II, in combination with other cytokines and growth factors, produces pro-apoptotic, pro-inflammatory, and pro-oxidant effects that may participate in the development of long term tissue injury [24-31]. RAS inhibitors act either by inhibiting $\mathrm{ACE}$ (ACEi), thereby blocking the conversion of Ang I to Ang II, or by antagonizing the binding of Ang II with either of its receptor subtypes [23]. Using the $\mathrm{ACEi}$, ramipril, we previously reported that chronic ramipril administration, initiated two weeks after $30 \mathrm{~Gy}$ focal irradiation of the rat brain, significantly mitigates the development of white matter necrosis in the optic tract [20-22]. Here we report that ramipril, administered 24 hours post-WBI and maintained daily for 12 weeks, reduces the deleterious effects of $10 \mathrm{~Gy}$-WBI, but not 15 Gy-WBI, on neurogenesis in the rat dentate gyrus. Ramipril also reduces the basal rate of granule cell neurogenesis in unirradiated control rats, suggesting that Ang II participates in maintaining granule cell neurogenesis.

\section{Methods}

Adult male Fischer 344 rats (Charles River Breeding Lab, Wilmington, MA) weighing between 200 and $240 \mathrm{~g}$ were used in all experiments. All animal procedures were performed in AAALAC accredited facilities, following institutionally approved protocols, in accordance with published recommendations for the proper care and use of laboratory animals. Food and water were provided ad libitum and consumption rates monitored daily. A total of 33 rats were randomly assigned to Radiation Treatment groups receiving WBI at prescribed doses of 0 (Control, $\mathrm{n}=9$ ), 10 Gy $(\mathrm{n}=16)$, and 15 Gy $(\mathrm{n}=8)$. Each of these Radiation Treatment groups was subdivided into drug treatment groups receiving either ramipril (RAM) or vehicle only (RAD), administered according to the same schedule. Ramipril therapy was initiated 24 hours post-WBI, and maintained continuously until sacrifice at 12 weeks post-WBI.

Rats were irradiated using a dedicated self-shielded $5000 \mathrm{Ci}{ }^{137} \mathrm{Cs}$ irradiator (Mark I, Model 68, J.L. Shepherd and Associates, San Fernando, CA), with a primary 
collimator used to create a $2 \mathrm{~cm} \times 30 \mathrm{~cm}$ rectangular dose field. Rats were anesthetized using ketamine $(80$ $\mathrm{mg} / \mathrm{kg})$ and xylazine $(8 \mathrm{mg} / \mathrm{kg})$ and positioned horizontally with their heads at the midpoint of this field (centered $15 \mathrm{~cm}$ above the base and $6 \mathrm{~cm}$ forward of the collimator face) to optimize uniformity of the dose distribution. Secondary lead shielding (1 cm thick) was used to limit radiation exposure to structures outside the brain including the jaw, pharynx, nose, and eyes. The head was oriented such that the radioactive source was lateral to the midline, with the $2 \mathrm{~cm}$ dose field dimension encompassing the anterior-posterior extent of the brain. To compensate for the affects of tissue attenuation, the prescribed radiation dose was administered bilaterally in two consecutive half-dose fractions. The measured dose rate at the time of irradiation was approximately $3.2 \mathrm{~Gy} /$ minute.

Ramipril treated rats (RAM subgroups) received a daily ramipril dose of approximately $1.5 \mathrm{mg} / \mathrm{kg}$ delivered by addition of the compound to their drinking water, whereas untreated rats (RAD subgroups) received bottle changes according the same schedule. The ramipril concentration in the drinking water was based on animal weight and the average ad libitum water consumption rate of approximately $20 \mathrm{ml} /$ day measured among our experimental animals. Ramipril is an ester-containing prodrug that is rapidly absorbed after oral intake and its absorption is not affected by food. Upon absorption, ramipril is metabolized by the liver and converted into its active form, ramiprilat, a potent ACE inhibitor. The bioavailability of ramipril is highly predictable and the stability of the drug in drinking water is superior to other ACE inhibitors. The drug also has the demonstrated ability to cross the blood-brain barrier, unlike many other clinically available ACE inhibitors [32,33].

Rats were sacrificed under deep pentobarbital anesthesia $(80 \mathrm{mg} / \mathrm{kg})$ by transcardial perfusion with saline $(300$ $\mathrm{ml})$ followed by $10 \%$ neutral buffered formalin $(300 \mathrm{ml})$. Brains were removed and post-fixed overnight at $4^{\circ} \mathrm{C}$ in $10 \%$ neutral buffered formalin, coronally sectioned into $2 \mathrm{~mm}$ blocks, and processed for paraffin embedding. Groups of four serial sections ( $7 \mu \mathrm{m}$ thickness) were cut at $50 \mu \mathrm{m}$ intervals along the rostral caudal axis of the hippocampus. Within each of these groups, one section was stained with hematoxylin-eosin (H\&E) for routine histological assessment, whereas the three remaining sections were stained immunohistochemically using antibodies for Ki-67 (1:100, 60 min, Thermo Fisher Scientific, Fremont, CA,), a selective marker of cellular proliferation; doublecortin (DCX; 1:100, overnight at $4^{\circ}$ C, Santa Cruz Biotechnology, Santa Cruz, CA), a selective marker of immature neurons; and CD68 (1:200, 30 min, AbD Serotec, Oxford, UK) a selective marker of activated microglia. Immunohistochemically stained sections were counter-stained using either hematoxylin (CD68) or DAPI (Ki-67 and DCX), as appropriate. For immunohistochemical processing, sections were deparaffinized and rehydrated, boiled for 10 minutes in $10 \mathrm{mM}$ citrate buffer, incubated with primary antibodies, and labeled with DAB (CD68; 4+ detection/Betazoid DAB: Biocare Medical) or Cy3 (Ki-67 and DCX; 1:250 Alexa 555 secondary, Invitrogen) per manufacturer's instructions.

All analyses were performed by individuals naïve to the experimental conditions using previously established methods [6,8,34-36]. Cell counts were performed bilaterally and exhaustively at $400 \times$ within the designated fields. Counts of Ki- $67^{+}$proliferating cells were performed within the SGZ (defined as the region extending $25 \mu \mathrm{m}$ on either side of the border between the hilus and the GCL), and were restricted to cells with uniform cytoplasmic staining of a clearly demarcated spherical or elliptical structure containing a spherical DAPI-stained nucleus. Counts of $\mathrm{DCX}^{+}$immature neurons were performed within the GCL and SGZ, and were restricted to cells with uniform cytoplasmic staining of a clearly demarcated spherical or pyramidal structure (often with dendritic processes extending through the GCL toward the molecular layer) containing a spherical DAPI-stained nucleus. Counts of $\mathrm{CD}^{+} 8^{+}$activated microglia were performed within the GCL and SGZ, and were restricted to cells with cytoplasmic staining of a small cell body and/ or microglial processes associated with an elliptical nucleus. The length of the SGZ at the GCL-hilar boarder and the volume of the SGZ and GCL were calculated for each section from which counts were obtained. SGZ lengths were used to standardize Ki-67 and DCX counts as linear densities. The SGZ and GCL volumes were used to normalize the CD68 counts as volume densities [34,35]. (Fig. 1)

The average linear density of $\mathrm{Ki}-67^{+}$cells residing within the SGZ and inferior margin of the GCL was used as measure of granule cell progenitor proliferation near the time of sacrifice for each rat. The average linear density of $\mathrm{DCX}^{+}$cells residing within the SGZ and GCL was used as a measure of neurogenic potential near the time of sacrifice for each rat. The average volume density of $\mathrm{CD} 8^{+}$cells residing within the SGZ and GCL was used as a measure of microglial activation for each rat. Group means and standard deviations were calculated from these data and, when necessary, log transformations were performed prior to analysis to adjust for unequal variances. These averages were statistically analyzed using analysis of variance (ANOVA) and Student's $t$ to test whether: 1 . Granule cell progenitor proliferation and/or neurogenesis were differentially affected in the Control group by RAM (relative to vehicle only); 2 . Granule cell progenitor proliferation and/or 


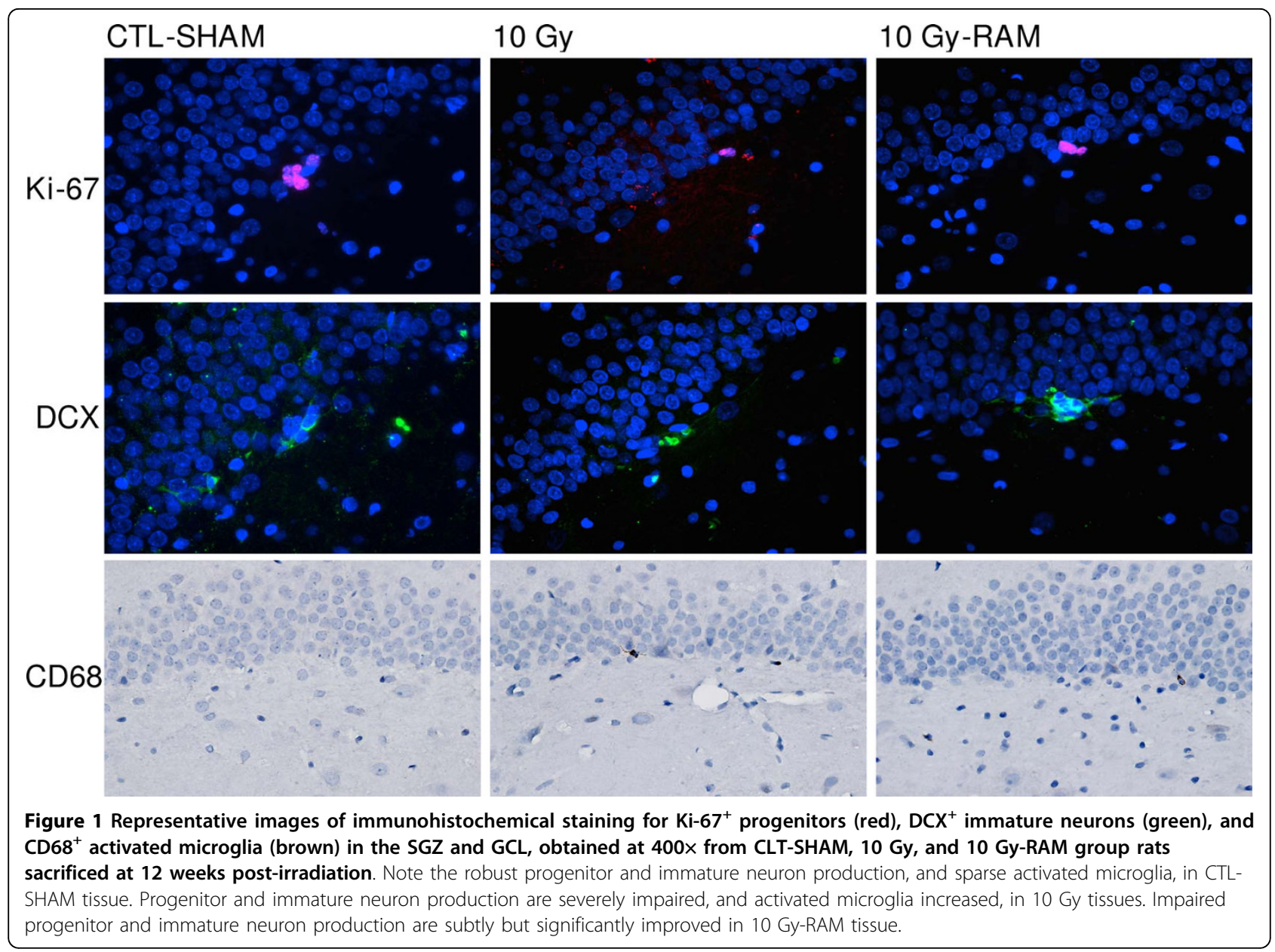

neurogenesis were decreased in the 10 Gy- and 15 GyWBI Radiation Treatment groups relative to Control; 3. Decreases in granule cell progenitor proliferation and/or neurogenesis in the 10 Gy- and 15 Gy-WBI Radiation Treatment groups were reduced by RAM (relative to vehicle only); and 4. Microlglial activation was increased in the 10 Gy- and 15 Gy-WBI Radiation Treatment groups relative to Control and whether these increases were reduced by RAM (relative to vehicle only) [37].

\section{Results}

Food and water intake and body weight among our animals were not affected by either radiation or ramipril treatment during 12 weeks of monitoring post-irradiation. In the Control group (CTL-SHAM), progenitor proliferation (Ki-67) within the SGZ did not differ between the Vehicle and RAM treatment groups; however, neurogenesis (DCX) was significantly $(\mathrm{p}<0.05)$ reduced by ramipril (Fig. 2). Ramipril (CTL-RAM) did not affect the density of $\mathrm{CD}^{+} 8^{+}$activated microglia relative to CTL-SHAM. Relative to Control, progenitor proliferation and neurogenesis within the SGZ were significantly reduced following 10 Gy- $(\mathrm{p}<0.001)$, and 15 Gy-WBI $(\mathrm{p}<0.001)$, accompanied by a significant increase in $\mathrm{CD}^{+} 8^{+}$activated microglia $(\mathrm{p}<0.001)$. The decrease in neurogenesis was radiation-dose dependent $(\mathrm{p}<0.01)$ (Fig. 2). Ramipril reduced the deleterious effects of radiation on progenitor proliferation $(\mathrm{p}<0.01)$ and neurogenesis $(\mathrm{p}<0.05)$ following $10 \mathrm{~Gy}-\mathrm{WBI}$, but was not effective following 15 Gy-WBI (Fig. 1). The mitigating effects of ramipril following 10 Gy-WBI were not accompanied by significant reductions in $\mathrm{CD} 68^{+}$ activated microglia counts (Fig. 3).

\section{Discussion}

Our results add to a growing body of evidence suggesting that RAS inhibitors can successfully reduce radiation-induced late effects. As expected, based on previous reports, 10 Gy- and 15 Gy-WBI produced dose-dependent decreases in progenitor proliferation (Ki-67) and neurogenesis (DCX) accompanied by a dose-dependent increase in microglial activation within the dentate gyrus $[5,9,19]$. Our use of the term neurogenesis here refers specifically to the neurogenic potential of the SGZ, as 

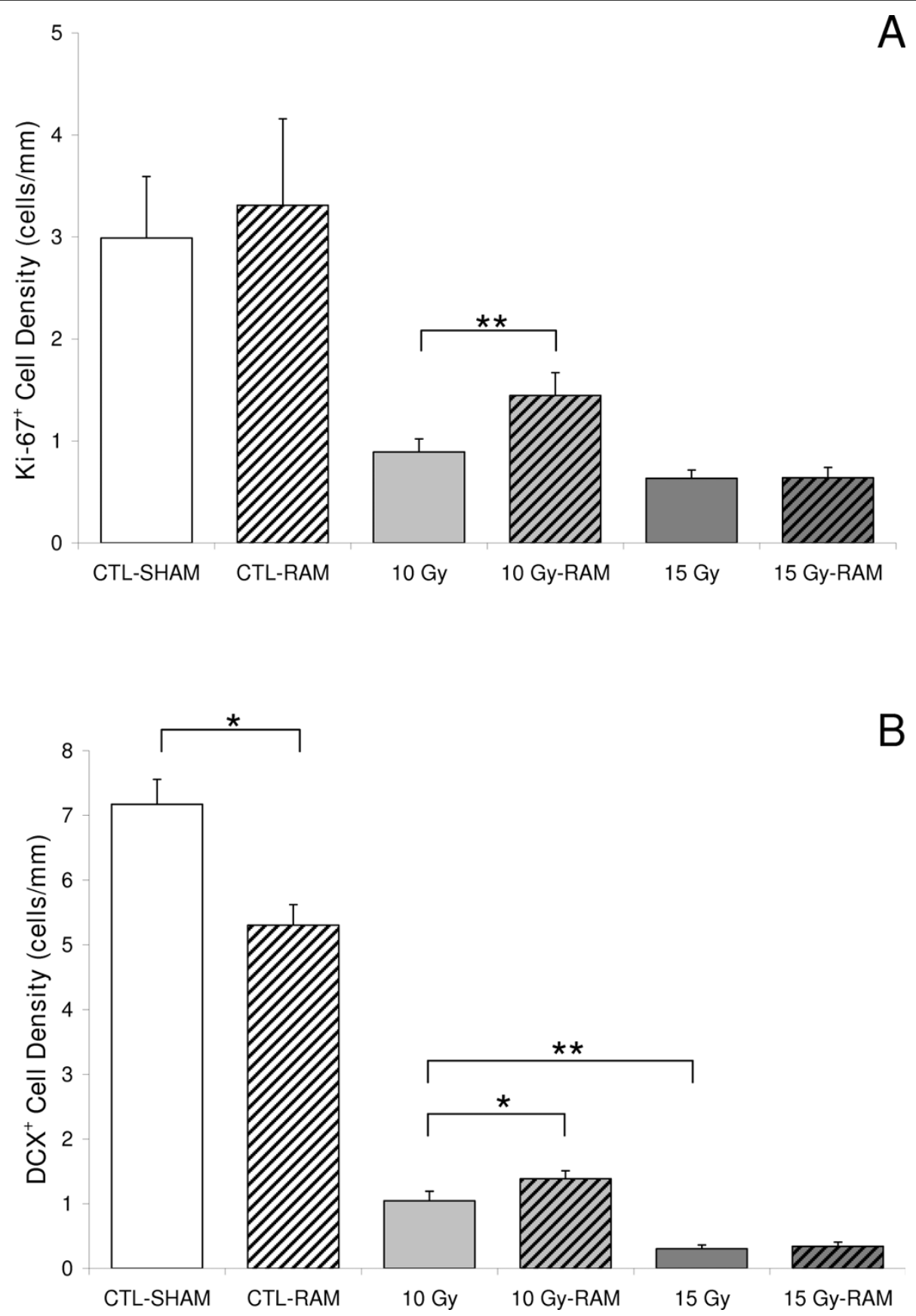

Figure 2 Linear densities of $\mathrm{Ki}-67^{+}$progenitors and $\mathrm{DCX}^{+}$immature neurons within the SGZ at 12 weeks post-irradiation. A. Relative to CTL-SHAM, Ki-67+ progenitor proliferation is significantly $(p<0.001)$ reduced following $10 \mathrm{~Gy}$ - and $15 \mathrm{~Gy}$-WBI. Ramipril mitigates the reduction in Ki-67 $7^{+}$progenitors following $10 \mathrm{~Gy}-\mathrm{WBI}(\mathrm{p}<0.05)$, but not following $15 \mathrm{~Gy}-\mathrm{WBI}$. B. Relative to CTL-SHAM, DCX ${ }^{+}$immature granule cell neurons are significantly $(p<0.001)$ and dose-dependently $(p<0.01)$ reduced following $10 \mathrm{~Gy}$ - and $15 \mathrm{~Gy}$-WBI. Ramipril mitigates the reduction in neurogenesis following $10 \mathrm{~Gy}-\mathrm{WBI}(\mathrm{p}<0.05)$, but not following $15 \mathrm{~Gy}$-WBI. Error bars represent the standard error of the mean for each treatment group. $\left({ }^{*}=p<0.05 ;{ }^{* *}=p<0.01\right)$.

evidenced by the induction of neuronal differentiation and the production of immature $\mathrm{DCX}^{+}$neurons within the SGZ microenvironment. Ramipril produced small but significant mitigating effects when administered following 10 Gy-WBI, but was not effective when administered following 15 Gy-WBI. The mitigating effects of ramipril were more pronounced for progenitor proliferation than they were for neurogenesis, suggesting that they may be mediated primarily by reducing radiation-induced apoptosis and/or mitotic catastrophes 



Figure 3 Volume densities of activated microglia measured within the SGZ and GCL at 12 weeks post-irradiation. A. Relative to CTLSHAM, CD68 ${ }^{+}$activated microglia in the SGZ are significantly $(p<0.001)$ and dose-dependently increased following 10 Gy- and 15 Gy-WBI. B. $\mathrm{CD}^{+} 8^{+}$activated microglia are unaffected by ramipril in either the Control group (CTL-SHAM vs. CTL-AVS) or in the 10 Gy-WBR group (10 Gy vs. 10 Gy-AVS). Thus, the mitigating effects of ramipril on granule cell progenitor proliferation and neurogenesis following $10 \mathrm{~Gy}$-WBI are not accompanied by a decrease in activated microglia. Error bars represent the standard error of the mean for each treatment group.

among progenitors and that the anti-inflammatory effects of ramipril may act less potently to mitigate radiation-induced disruption of neurogenic signaling within the SGZ. Ang II, acting primarily via AT2R, is a well established promoter of trauma-induced apoptosis in a variety of tissues, including brain, and administering AT2R antagonists has been shown to prevent Ang IIinduced apoptosis [24-26]. Thus, inhibiting the production of Ang II with ramipril may similarly reduce apoptosis among neural progenitors within the SGZ following radiation injury. The rather limited mitigating effects produced by ramipril in this context may reflect that fact that the majority of radiation-induced apoptosis among progenitors within the SGZ occurs within 24 hours post-irradiation, preceding the initiation of ramipril therapy [35].

Cytostatic effects may also have contributed to the mitigation produced by ramipril in this context. In the Control group, ramipril significantly reduced neurogenesis without reducing progenitor proliferation within the SGZ, suggesting that the signaling required for neuronal (versus astrocytic) differentiation among these progenitors was selectively inhibited by ramipril. Cytostatic effects of ACEi and Ang II receptor antagonists are well 
established in vitro in a variety of normal and neoplastic cells [38], and also in vivo where they arrest fibroblast proliferation and regulate proliferation and migration of endothelial cells [39]. Mukuda et al. [40] recently reported that daily administration of the AT1R antagonist, losartan, maintained for 2 weeks suppresses running-enhanced increases in granule cell progenitor proliferation in the rat SGZ without affecting the basal proliferation rate. Ramipril's suppression of the basal rate of neurogenesis in the CTL-RAM group may reflect its different mechanism of action, since ACE inhibitors deprive both AT1R and AT2R of their substrate whereas losartan antagonizes only the AT1R. Alternatively, it may reflect the much longer duration of therapy and/or the relatively high dose of ramipril used in our study, which was approximately twice the standard clinical dose [41]. Both losartan and ramipril cross the bloodbrain barrier and are thus able to influence the brain RAS system directly [42]. Ang II has been implicated as a promoter of vascular endothelial growth factor (VEGF) synthesis [41] and as a modulator of N-methylD-aspartate (NMDA)-glutamate receptor function $[13,23]$. Both of these processes are capable of acutely affecting the rate of neurogenesis within the SGZ and might therefore play a role in maintaining the basal rate of neurogenesis as well [40].

The mitigating effects of ramipril following $10 \mathrm{~Gy}$ WBI were not accompanied by changes in the numbers of activated microglia, suggesting that the anti-inflammatory effects of ramipril may not have played a significant role. This observation lends additional support to an anti-apoptotic mechanism being primary in this regard. However, it is possible that ramipril produced anti-inflammatory/anti-oxidant effects by antagonizing the actions of IL- 6 , TNF- $\alpha$, MCP-1, or other cytokines, without affecting the numbers of activated microglia [43]. It is also possible that radiation does not produce deleterious effects on progenitor proliferation and/or neuronal differentiation within the SGZ, but rather selectively suppresses expression of the two proteins we assayed as measures of these processes, i.e. Ki-67 and CD68, respectively. However, the results of numerous publications using a variety of assays for cellular proliferation and granule cell neurogenesis suggest this as an unlikely possibility [4-14]. Finally, the relevance of impaired granule cell neurogenesis to late delayed cognitive deficits has been called into question by recent reports indicating that such deficits can manifest in behavioral paradigms that are not conventionally viewed as hippocampal-dependent and at very long latencies (> 3 months) post-irradiation [44].

\section{Conclusions}

Collectively our results add to the existing body of knowledge regarding the radiation dose-dependence of WBI effects on progenitor proliferation and neurogenesis within the SGZ, and establish that ramipril has the capacity to reduce the deleterious effects of WBI in this context. Though significant, the magnitude of these effects does not suggest the treatment regimen employed here as a promising therapeutic strategy in this regard. However, it is possible that these assays are not sufficiently inclusive and that the deleterious effects of irradiation on other processes pertinent to learning and memory are more potently mitigated by ramipril. More potent mitigating effects might also be achieved by administering ramipril at lower doses and/or for shorter durations, or in combination with other antiapoptotic, anti-inflammatory or anti-oxidant therapies. Addressing these experimental issues will be the focus of future investigations.

\section{Acknowledgements}

This study was supported by NIH U19A1067734-010005 (JHK). The authors also wish to acknowledge the contributions of Christina Liccardello, Kelli McDonough, and Jegor Korzyukov for assistance with image acquisition and cell counting.

\section{Author details}

'Henry Ford Hospital, Department of Neurosurgery, 3074 E\&R Building, 2799 W Grand Boulevard, Detroit, Michigan 48202, USA. ${ }^{2}$ Henry Ford Hospital, Department of Radiation Oncology, HFH-M2, 2799 W Grand Boulevard, Detroit, Michigan 48202, USA.

\section{Authors' contributions}

KAJ directed the project, performed cell counting, assisted with immunohistochemistry, and drafted the manuscript.

SLB co-directed the project and assisted with WBI.

$J \mathrm{~L}$ administered $\mathrm{WBI}$ and experimental drugs, and performed perfusions and cell counting.

AK administered WBI and experimental drugs, and assisted with perfusions. $\mathrm{KL}$ performed immunohistochemistry.

JHK directs the laboratory.

All authors read and approved the final manuscript.

\section{Competing interests}

The authors declare that they have no competing interests.

\section{Received: 10 August 2009}

Accepted: 1 February 2010 Published: 1 February 2010

\section{References}

1. Bromet EJ, Havenaar JM: Psychological and perceived health effects of the Chernobyl disaster: a 20-year review. Health Phys 2007, 93:516-521.

2. Gamache GL, Levinson DM, Reeves DL, Bidyuk PI, Brantley KK: Longitudinal neurocognitive assessments of Ukrainians exposed to ionizing radiation after the Chernobyl nuclear accident. Arch Clin Neuropsychol 2005, 20:81-93.

3. Abayomi OK: Pathogenesis of cognitive decline following therapeutic irradiation for head and neck tumors. Acta Oncol 2002, 41:346-351.

4. Palmer TD, Willhoite AR, Gage FH: Vascular niche for adult hippocampal neurogenesis. Comp Neurol 2000, 425:479-494.

5. Jeltsch H, Bertrand F, Lazarus C, Cassel JC: Cognitive performances and locomotor activity following dentate granule cell damage in rats: Role of 
lesion extent and type of memory tested. Neurobiol Learn Mem 2001, 76:81-105.

6. Monje ML, Mizumatsu S, Fike JR, Palmer TD: Irradiation induces neural precursor-cell dysfunction. Nature Med 2002, 8:955-962.

7. Monje ML, Palmer TD: Radiation injury and neurogenesis. Curr Opin Neurol 2003, 16:129-134.

8. Mizumatsu S, Monje ML, Morhardt DR, Rola R, Palmer TD, Fike JR: Extreme sensitivity of adult neurogenesis to low doses of X-irradiation. Cancer Res 2003, 63:4021-4027.

9. Monje ML, Toda H, Palmer TD: Inflammatory blockade restores adult hippocampal neurogenesis. Science 2003, 302:1760-1765.

10. Rola R, Raber J, Rizk A, Otsuka S, VandenBerg SR, Moreherdt DR, Fike JR: Radiation-induced impairment of hippocampal neurogenesis is associated with cognitive deficits in young mice. Exp Neurol 2004 188:316-330.

11. Saxe MD, Battaglia F, Wang JW, Mallert G, David DJ, Monckton JE, Garcia ADR, Sofroniew MV, Kandel ER, Santarelli L, Hen R, Drew MR: Ablation of hippocampal neurogenesis impairs contextual fear conditioning and synaptic plasticity in the dentate gyrus. PNAS 2006, 103:17501-17507.

12. Andres-Mach M, Rola R, Fike JR: Radiation effects on neural precursor cells in the dentate gyrus. Cell Tissue Res 2008, 331:251-262.

13. Bruel-Jungerman E, Davis S, Rampon C, Laroche S: Long-term potentiation enhances neurogenesis in the adult rat. J Neurosci 2006, 26:5888-5893.

14. Laroche S, Doyre V, Bloch V: Linear relation between the magnitude of long-term potentiation in the dentate gyrus and associative learning in the rat. A demonstration using commissural inhibition and local infusion of an N-methyl, D. aspartate receptor antagonist. Neurosci 1989, 28:375-386.

15. Yamashima T, Tonchev AB, Vachkov IH, Popivanova BK, Seki T, Sawamoto K, Okano H: Vascular adventitia generates neuronal progenitors in the monkey hippocampus after ischemia. Hipp 2004, 14:861-875.

16. Conover JC, Notti RQ: The neural stem cell niche. Cell Tissue Res 2008, 331:211-224.

17. Madsen TM, Kristjansen PEG, Bolwig TG, Wortwein G: Arrested neuronal proliferation and impaired hippocampal function following fractionated brain irradiation in the adult rat. Neurosci 2003, 119:635-642.

18. Hwang SY, Jung JS, Kim TH, Lim SJ, Oh ES, Kim JY, Ji KA, Cho KH, Han IO lonizing radiation induces astrocyte gliosis through microglia activation. Neurobiology of Disease 2006, 21:457-467.

19. Ramanan S, Kooshki M, Zhao W, Hsu FS, Riddle DR, Robbins ME: The PPAR $\alpha$ agonist fenofibrate preserves hippocampal neurogenesis and inhibits microglial activation after whole-brain irradiation. Int J Radiation Oncology Biol Phys 2009, 75:870-877.

20. Kim JH, Brown SL, Kolozsvary A, Jenrow KA, Ryu S, Rosenblum ML, Carretero OA: Modification of radiation injury by Ramipril, inhibitor of angiotensin-converting enzyme, on optic neuropathy in the rat. Radiat Res 2004, 161:137-142.

21. Ryu S, Kolozsvary A, Jenrow KA, Brown SL, Kim JH: Mitigation of radiationinduced optic neuropathy in rats by ACE inhibitor ramipril: importance of ramipril dose and treatment time. J Neurooncol 2007, 82:119-124.

22. Kim JH, Brown SL, Jenrow KA, Ryu S: Mechanisms of radiation-induced brain toxicity and implications for future clinical trials. J Neurooncol 2008, 87:279-286.

23. Von Bohlen O, Albrecht HD: The CNS renin-angiotensin system. Cell Tissue Res 2006, 326:599-616.

24. Bonnet F, Cao Z, Cooper ME: Apoptosis and Angiotensin II: Yet Another Renal Regulatory System?. Exp Nephrol 2001, 9:295-300.

25. Horiuchi M, Akishita M, Dzau VJ: Molecular and cellular mechanism of angiotensin II-mediated apoptosis. Endocrine Res 1998, 24:307-314.

26. Shenoy UV, Richards EM, Huang X-C: Angiotensin II type 2 receptormediated apoptosis of cultured neurons from newborn rat brain. Endocrinology 1999, 140:500-509.

27. Robbins ME, Diz DI: Pathogenic role of the renin-angiotensin system in modulating radiation-induced late effects. Int I Radiation Oncology Biol Phys 2006, 64:6-12.

28. Griendling KK, Minieri CA, Ollerenshaw JD, Alexander RW: Angiotensin II stimulates NADH and NADPH oxidase activity in cultured vascular smooth muscle cells. Circ Res 1994, 74:1141-1148.

29. Liu YH, Yang XP, Sharov VG, Nass O, Sabbah HN, Peterson E, Carretero OA Effects of angiotensin-converting enzyme inhibitors and angiotensin II type 1 receptor antagonists in rats with heart failure. Role of kinins and angiotensin II type 2 receptors. J Clin Invest 1997, 99:1926-35.

30. Mehta JL, Hu B, Chen J, Li D: Pioglitazone inhibits LOX-1 expression in human coronary artery endothelial cells by reducing intracellular superoxide radical generation. Arterioscler Thromb Vasc Biol 2003, 23:2203-2208.

31. Tojo A, Onozato ML, Kobayashi N, Goto A, Matsuoka H, Fujita T: Angiotensin II and oxidative stress in Dahl Salt-sensitive rat with heart failure. Hypertension 2002, 40:834-839.

32. Jackson EK, Garrison JC: Renin and Angiotensin. Goodman \& Gilman's The Pharmacological Basis of Therapeutics New York: McGraw Hill, 10 2003, 744.

33. Yang XP, Liu YH, Mehta D, Cavasin M, Shesely E, Xu J, Liu F, Carretero OA: Diminished cardioprotective response to inhibition of ACE and angiotensin II type 1 receptor in B2 kinin receptor gene knockout mice. Cir Res 2001, 88:1072-1079.

34. Schindler MK, Forbes ME, Robbins ME, Riddle DR: Ageing-dependent changes in the radiation response of the adult rat brain. Int I Radiation Oncology Biol Phys 2007, 70:826-834.

35. Uberti D, Piccioni L, Cadei M, Grigolato P, Rotter V, Memo M: p53 is dispensable for apoptosis but controls neurogenesis of mouse dentate gyrus cells following $\gamma$-irradiation. Mol Brain Res 2001, 1:81-89.

36. Rola R, Zou Y, Huang TT, Fishman K, Baure J, Rosi S, Milliken H, Limoli CL, Fike JR: Lack of extracellular superoxide dismutase (EC-SOD) in the microenvironment impacts radiation-induced changes in neurogenesis. Free Radic Biol Med 2007, 42:1133-1145.

37. SAS Institute Inc: SAS/STAT 9,1 Users Guide Cary, NC: SAS Institute Inc 2004.

38. Charrier S, Michaud A, Badaoui S, Giroux S, Ezan E, Sainteny F: Inhibition of angiotensin I-converting enzyme induces radioprotection by preserving murine hematopoietic short-term reconstituting cells. Blood 2004, 104:978-985

39. Molteni A, Ward WF, Ts'ao CH, Taylor J, Small W, Brizio-Molteni L, Veno PA: Cytostatic properties of some angiotensin converting enzyme inhibitors and of angiotensin II Type I receptor agonists. Current Pharmaceutical Design 2003, 9:751-761.

40. Mukuda T, Sugiyama H: An angiotensin II receptor antagonist suppresses running-enhanced hippocampal neurogenesis in rat. Neurosci Res 2007, 58:140-144.

41. Otani A, Takagi H, Oh H, Suzuma K, Matsumura M, Ikeda E, Honda Y: Angiotensin II-stimulated vascular endothelial growth factor expression in bovine retinal pericytes. Invest Opthalmol Vis Sci 2000, 41:1192-1199.

42. Otani A, Takagi H, Suzuma K, Honda Y: Angiotensin II potentiates vascular endothelial growth factor-induced angiogenic activity in retinal microcapillary endothelial cells. Circ Res 1998, 82:619-628.

43. Sandmann S, Li J, Fritzenkotter C, Spormann J, Tiede K, Fischer JW, Unger T: Differential effects of olmesartin and ramipril on inflammatory response after myocardial infarction. Blood Press 2006, 15:116-128.

44. Robbins ME, Payne V, Tommasi E, Diz DI, Hsu FC, Brown WR, Wheeler KT, Olson J, Zhao W: The $\mathrm{AT}_{1}$ receptor antagonist, L-158,809, prevents or ameliorates fractionated whole-brain irradiation-induced cognitive impairment. Int J Radiation Oncology Biol Phys 2009, 73:499-505.

doi:10.1186/1748-717X-5-6

Cite this article as: Jenrow et al:: Ramipril mitigates radiation-induced impairment of neurogenesis in the rat dentate gyrus. Radiation Oncology 2010 5:6.

\section{Submit your next manuscript to BioMed Central and take full advantage of:}

- Convenient online submission

- Thorough peer review

- No space constraints or color figure charges

- Immediate publication on acceptance

- Inclusion in PubMed, CAS, Scopus and Google Scholar

- Research which is freely available for redistribution 